\title{
SUPERFÍCIES PARAMÉTRICAS: UMA APLICAÇÃO NO DESENHO DE EMBALAGENS PARA FRUTAS
}

\author{
Débora Silveira da Costa \\ Universidade Federal do Rio Grande do Sul \\ debora.vitola@gmail.com \\ Diego Jucá de Lima Oliveira \\ Universidade Federal do Rio Grande do Sul \\ diegojuk@gmail.com \\ Fábio Gonçalves Teixeira \\ Universidade Federal do Rio Grande do Sul \\ fabiogt@ufrgs.br \\ Felix Bressan \\ Universidade Federal do Rio Grande do Sul \\ felix.bressan@gmail.com \\ Tânia Sulzbacher \\ Universidade Federal do Rio Grande do Sul \\ tania.sulzbacher@gmail.com \\ Underléa Miotto Bruscato \\ Universidade Federal do Rio Grande do Sul \\ Underleia.bruscato@ufrgs.br
}

\begin{abstract}
Resumo: Este artigo descreve o processo de projeto de embalagem intermediária para transporte de frutas, que foi desenvolvida a partir da proposição de utilizar-se o Plug-in GrassHopper para geração e modelagem paramétricas. Partiu-se de uma situação inicial bem definida, que estabelecia o caráter de flexibilidade dimensional para um grupo de frutas de morfologia semelhante. $O$ resultado apresenta um conjunto com dois elementos distintos: o primeiro, uma superfície com nichos próprios para o acondicionamento de frutas; e o segundo, uma grade estrutural que permite o afastamento vertical das frutas, bem como, permite o empilhamento de diversas camadas de superfícies.
\end{abstract}

Palavras-chave: Modelagem Paramétrica, Design, Embalagens. 


\section{INTRODUÇÃO}

O presente estudo partiu da proposta de desenvolvimento de produto caracterizado pela utilização da modelagem paramétrica como estratégia de processo de design para geração de alternativas de embalagens intermediárias para transporte de frutas, objetivando otimizar os resultados das alternativas geradas para potencializar as suas adequações e ajustes. O experimento foi proposto na disciplina de Fabricação Digital do Programa de Pós-Graduação em Design da Universidade Federal do Rio Grande do Sul que desenvolveu-se entre os meses de Agosto à Dezembro de 2013.

O tema usado no experimento, surgiu após uma dinâmica de grupo que elegeu o desperdício de alimentos como ponto de partida para a problematização. Em seguida, os sub-problemas foram identificados e circunscrito o transporte de frutas como escopo principal da Situação Inicial.

De acordo com os recentes dados da FAO - Divisão de Alimentação e Agricultura da ONU - Organização das Nações Unidas, "o desperdício de alimentos é um problema global, onde cerca de um terço de todos os alimentos produzidos para consumo humano é perdido ou desperdiçado - aproximadamente 1,3 bilhão de toneladas, totalizando 750 bilhões de dólares anuais".A FAO observou ainda, "que a maior parte das perdas de alimentos acontece nas fases de pós-produção, como colheita, transporte e armazenamento".

Inicialmente foi utilizado o jogo Creative Sketch (figura 1) desenvolvido por (CARDOSO, 2012), conforme a autora, trata-se de um jogo para identificação de uma resolução criativa de problemas, que os autores utilizaram para desencadear operações criativas para soluções do problema.

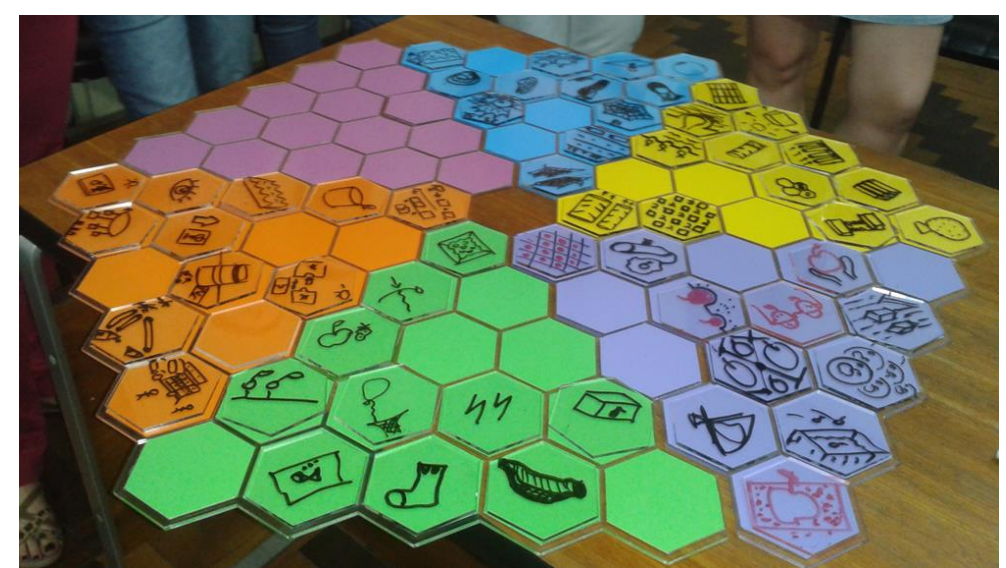

Figura 1 - Creative Sketch.

\section{PROJETO INFORMACIONAL}

Para Rozenfeld, et. al. (2008), o projeto informacional consiste na etapa de desenvolvimento projetual que orienta o correto entendimento do problema de projeto, analisa diferentes ciclos de vida do produto e os relaciona com os clientes, transforma as necessidades dos clientes em requisitos do projeto e estrutura as especificações meta do produto. 


\subsection{Embalagens para Transporte de Frutas}

As deficiências relacionadas às embalagens, que de acordo com a Embrapa Empresa Brasileira de Pesquisa Agropecuária, comprometem a perda de 39\% das frutas e hortaliças no caminho entre a lavoura e o consumidor, levaram o governo brasileiro a aportar cerca de 7,5 milhões em 2010, em um projeto de desenvolvimento de embalagens mais adequadas ao transporte, inclusive para exportação. Estes dados são da área de Desenho Industrial do Instituto Nacional de Tecnologia (INT/MCTI), que recebeu a missão de propor alternativas de embalagens para o acondicionamento de caquis, mamões papaya, mangas, morangos e palmitos de pupunha.

Ainda segundo o INT/MCTI (2013), as caixas de madeira, amplamente usadas no Brasil, além de anti-higiênicas, comprimem a maioria dos frutos, que ficam machucados à medida que sofrem impactos, vibrações e são empilhados durante o transporte e armazenamento. As versões em papelão ou plástico, por sua vez, apesar de algumas vantagens, não se adequam aos diferentes tipos de frutas, permitem o contato entre as cascas e dificultam a ventilação, fazendo a fruta liberar a substância etileno que acelera o processo de amadurecimento.

Sendo assim, o Instituto (INT) desenvolveu um sistema que consiste numa base padronizada na largura e comprimento, com três alturas diferentes para comportar dimensões distintas de frutos. A essa base - que se empilha em módulos perfeitos sobrepõem-se, mantendo espaço para a ventilação, uma bandeja fina, que tem inúmeras concavidades apropriadas ao exato tamanho de cada fruto. A precisão da acomodação da fruta é garantida por pesquisa realizada com frutas digitalizadas em scanner 3D e testes com as amostras impressas em máquinas de prototipagem rápida, que facilitam a manipulação dos volumes e a continuidade da pesquisa fora das safras. Feita em material plástico resistente, após o transporte, a base dobra e retorna ao produtor. A bandeja, que segue até a prateleira ou consumidor final, é reciclável, devendo ser produzida em materiais compósitos que aproveitam as fibras dos resíduos da colheita, desenvolvidos pelo IMA-UFRJ.

De acordo com as informações disponíveis no sítio virtual do INT/MCTI, as avaliações da solução foram realizadas pela Embrapa Agroindústria de Alimentos nas embalagens desenvolvidas para morangos comprovam que, sob refrigeração, sem adição de qualquer elemento, os frutos acondicionados com essa tecnologia duram até 15 dias, ou seja, $50 \%$ a mais do que nas embalagens atuais.

\subsection{Modelagem Paramétrica}

A capacidade de reconfigurar uma série de parâmetros pré-definidos, alterando rapidamente o desenho final, não necessitando refazer todo trabalho, faz da modelagem paramétrica uma importante aliada no desenvolvimento de projetos, principalmente nas fases de prototipação e testes. No âmbito do projeto de artefatos, este fato tem permitido viabilizar geometrias complexas, introduzindo a possibilidade de criar e manipular novas famílias de formas e superfícies atendendo a expectativas de prazos reduzidos. A ferramenta utilizada no desenvolvimento do presente projeto foi o software Rhinoceros ${ }^{\circledR}$ juntamente com o plug-in GrassHopper.

\subsection{Fabricação Digital}


A fabricação digital vem se transformando em uma alternativa de processo de produção revolucionária pelo seu impacto no que tange a solução de problemas complexos. De acordo com a matéria da revista The Economist, publicada em outubro de 2013, a fabricação digital permite a confecção em peça única de objetos que antes só poderiam ser construídas por componentes em função das restrições de geometria disponíveis nos processos convencionais. Segundo a Revista Época "a escova Blizzident (figura 2) é resultado de uma das aplicações mais promissoras da impressão 3D: a personalização de objetos do dia a dia usando nossos corpos como modelo. [...] É uma espécie de molde dos dentes com cerdas, que o usuário coloca na boca e mastiga por seis segundos. Como tem exatamente o formato dos seus dentes, deixa-os todos limpos e escovados com facilidade".

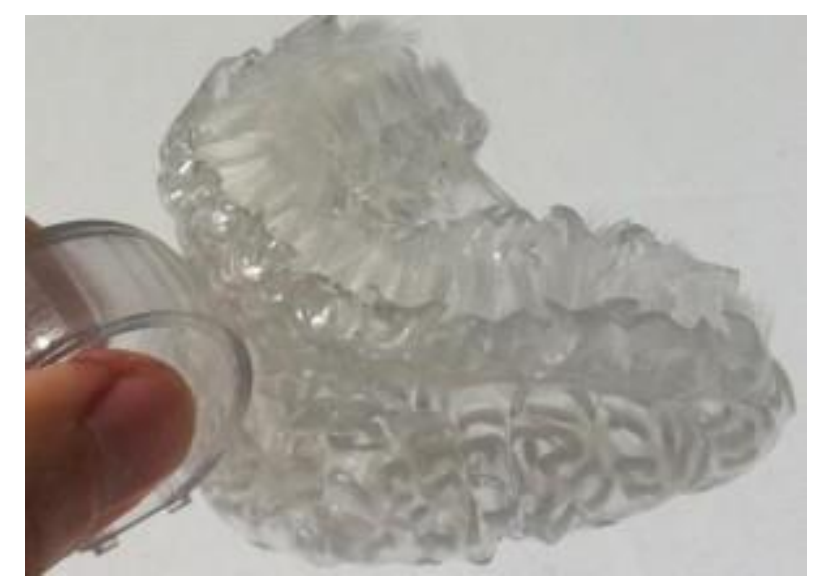

Figura 2 - molde dos dentes com cerdas.

Isto acarreta numa mudança de paradigma nas bases conceituais dos projetos, pois têm-se uma maior liberdade para explorar formas e geometrias. O resultado disso, é uma aplicação em todas as ordens de escala que vai de objetos comuns de uso no cotidiano, até a confecção de chassis de automóveis.

Portanto, percebeu-se uma oportunidade de aplicar estes novos conceitos de desenvolvimento de geometrias, nas alternativas que foram propostas para as estruturas de acondicionamento das frutas, que contemplasse uma solução para as fases de colheita-transporte-exposição, privilegiando o aspecto morfológico.

\subsection{Metodologia Projetual}

Segundo Bonfim(1995), "o bom resultado de um projeto depende da capacidade técnica e criativa de quem o desenvolve. Métodos e técnicas podem, contudo, auxiliar na organização das tarefas tornando-as mais claras e precisas, ou seja, oferecem suporte lógico ao desenvolvimento de um projeto." Neste trabalho, a metodologia sugerida por Bonsiepe (1984) é usada associada ao processo criativo de Gomes (2011).

\subsubsection{Análise de Uso}

A análise de uso, definida por Bonsiepe (1984), como a etapa de projeto que busca" detectar pontos negativos e criticáveis", sendo conveniente utilizar registros 
fotográficos para documentá-los, deu prioridade para a observação do uso recorrente de engradados de materiais polímeros. É comum encontrá-los em toda cadeia produtiva, deste a coleta até a chegada da fruta ao ponto de venda (figura 3 ).

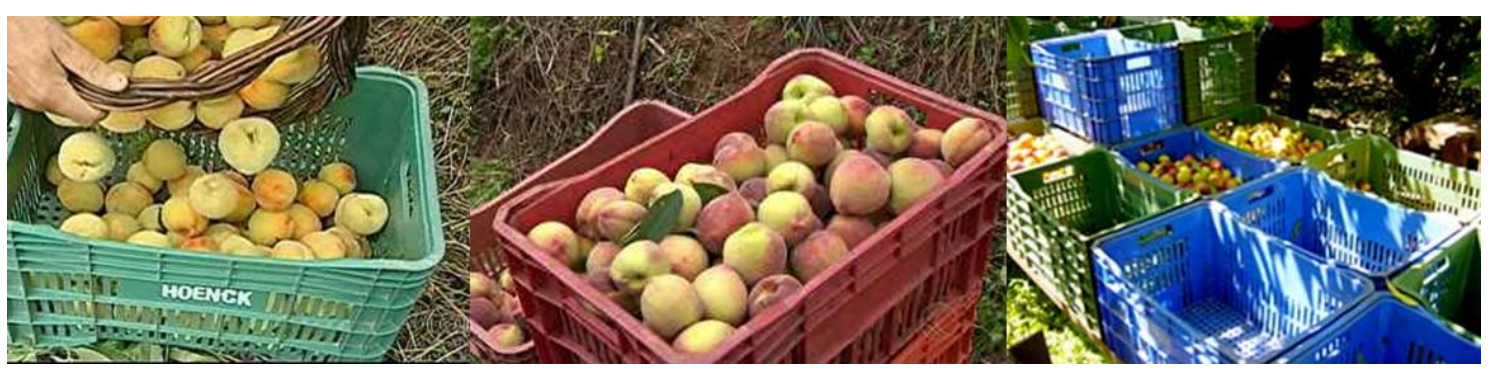

Figura 3 - Análise de Uso.

No Brasil, o principal transporte das frutas é através dos caminhões e caminhonetes. $\mathrm{E}$, apesar do transporte desses produtos terem evoluído bastante ao longo dos anos, ainda é possível encontrar produtores de pequenas unidades agrícolas que transportam em automóveis comuns.

Além disso, temos a predominância de transporte em caminhões cobertos com lonas, sem controle de temperatura, geralmente quando as frutas têm baixo valor agregado. Para tanto, elas são colhidas prematuramente, anterior ao seu amadurecimento e ainda assim, não é possível evitar uma grande perda desses produtos.

As frutas são colhidas e colocadas em caixas (figura 4), sem nenhuma separação. Frutas delicadas como: pêssegos, figos e peras; sofrem com o impacto desse empilhamento, chegando danificadas no seu destino final.

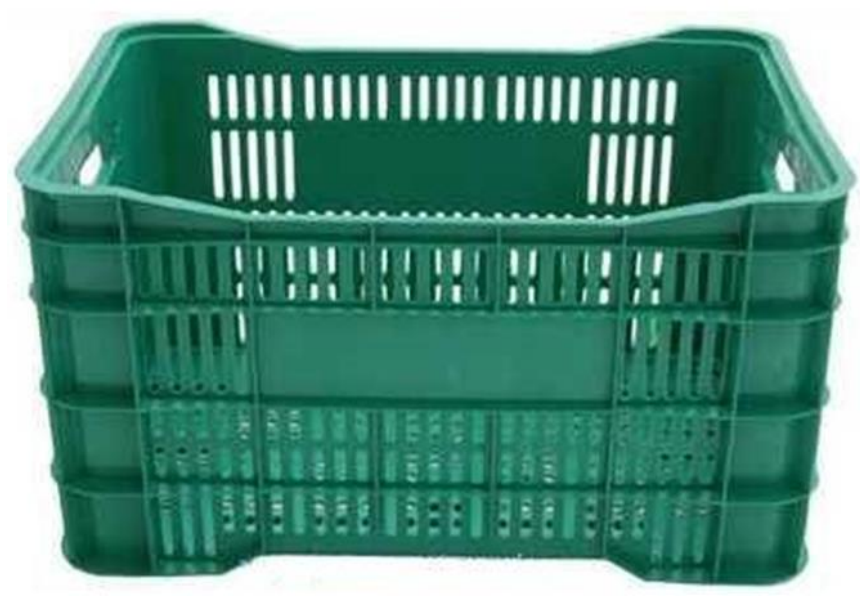

Figura 4 - Caixas de frutas padrão.

\subsubsection{Análise Morfológica}

“(...) a análise morfológica serve para reconhecer e compreender a estrutura formal (concepção formal) de um produto, vale dizer, sua composição, partindo de elementos geométricos e suas transições (encontros). Inclui também 
informações sobre acabamento e tratamento de superfícies."

(BROD JÚNIOR, GOMES E MEDEIROS; 2010).

As frutas selecionadas para o estudo foram: maça, pêssego, figo e pera (figura 5). Dentre as frutas escolhidas, a maçã é que mais resiste a impactos, pois o pêssego, 0 figo e a pera são frutas mais delicadas e com qualquer batida, ficam danificadas, e conforme mencionado acima, esse impacto faz com que a fruta libere uma substância chamada etileno que acelera o processo de amadurecimento.

As quatro frutas escolhidas possuem uma morfologia semelhante, que facilita o seu encaixe nas estruturas desenvolvidas. A maçã e a pera se aproximam em volume e o mesmo ocorre com o pêssego e o figo.
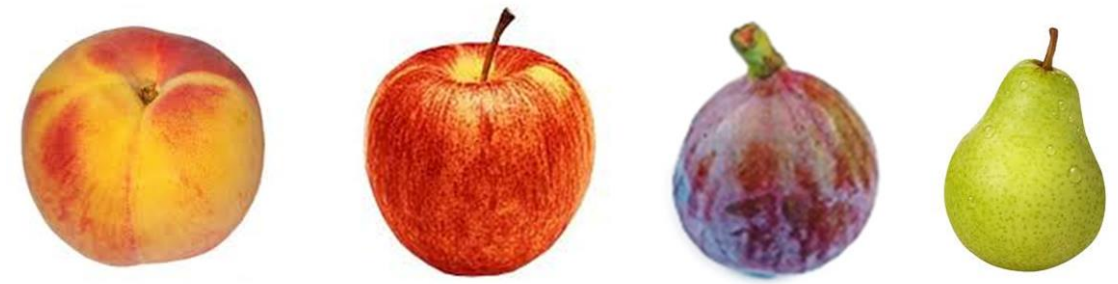

Figura 5 - Análise morfológica das frutas utilizadas.

\subsubsection{Lista de Requisitos}

Para Bonsiepe (1984), "a lista de requisitos serve para orientar o processo projetual em relação às metas a serem atingidas. Convém formular cada requerimento separadamente, e utilizar uma forma comum (frases positivas, sem negação). Se for possível, alguns dos requerimentos devem ser representados em termos quantitativos."

Tabela 1 - lista de Requisitos

\begin{tabular}{ll}
\hline & Requisitos \\
\hline Incondicionais & Mostrar proteção; \\
& Demostrar segurança; \\
& Ser leve; \\
\hline Desejáveis & Ser macio; \\
& Possuir fácil manuseio; \\
& Ser fácil de limpar; \\
\hline Parâmetro 5 & Possuir o menor número de peças \\
& possível; \\
\hline
\end{tabular}

Fonte: Elaborado pelo autor, com base na pesquisa realizada.

\section{PROJETO CONCEITUAL}

Foram testadas inúmeras formas na superfície principal. A fim de acomodar as frutas da melhor maneira possível. No projeto conceitual o uso da geometria, aliada a uma programação que maximize os refinamentos da morfologia através do plugin Grasshopper foi imprescindível para o andamento do projeto. Abaixo (figura 6) demostramos alguns modelos gerados durante o processo. 


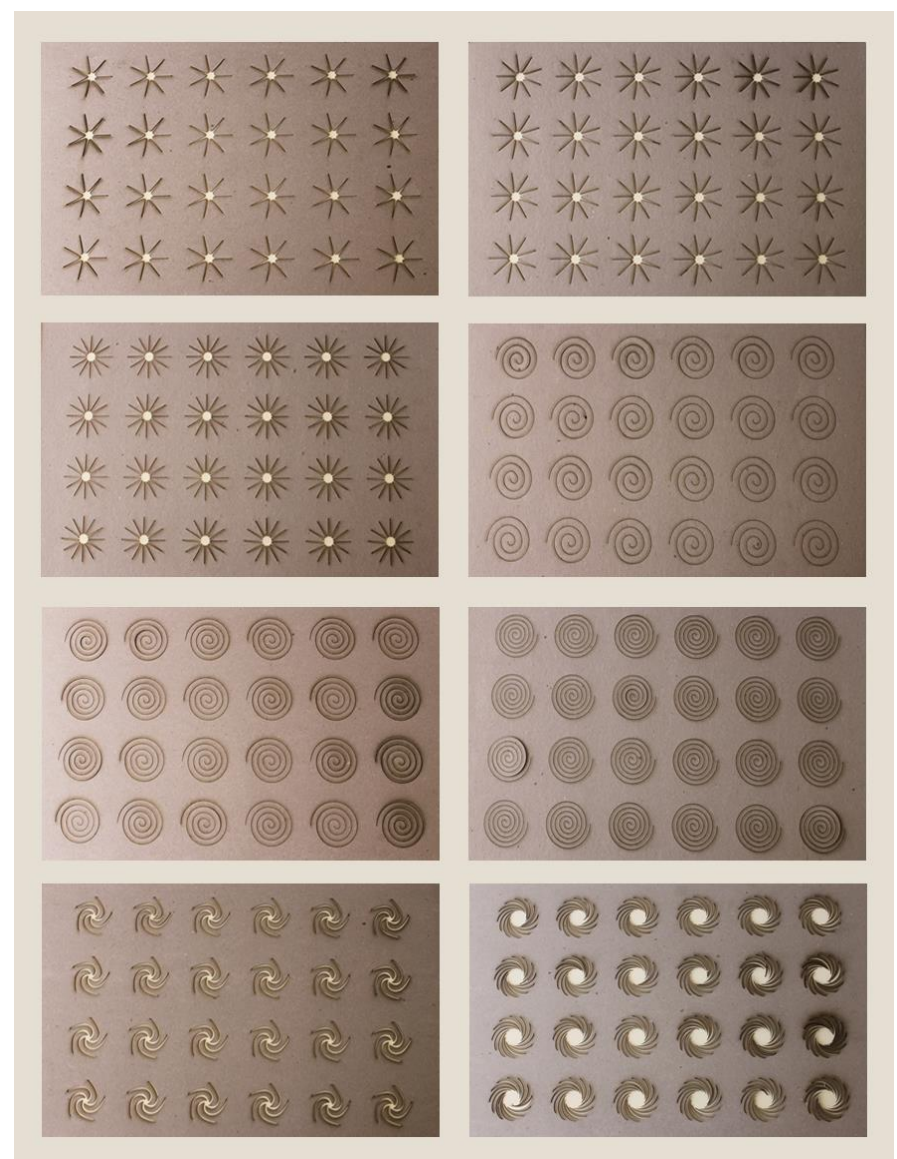

Figura 6 - Projeto Conceitual.

Alguns modelos foram desenvolvidos e variações deles foram possíveis através da ferramenta utilizada. Dando a possibilidade de modificar e prototipar de forma rápida.

Seguem algumas imagens (figuras 7, 8, 9 e 10) da programação paramétrica no software Rhinoceros ${ }^{\circledR}$ com o plugin Grasshopper. Foram implementados dois tipos de rotinas. Uma gera "estrelas" onde pode-se, mudando os parâmetros, alterar o número de pontas, quantidade, localização, dimensão do arredondamento das pontas e reentrâncias. Esse módulo é diretamente relacionado com o módulo de geração dos "waffles". Onde alterações feitas num deles se refletem no outro. As estrelas sempre vão ficar centralizadas e adequadas às dimensões dos "waffles".

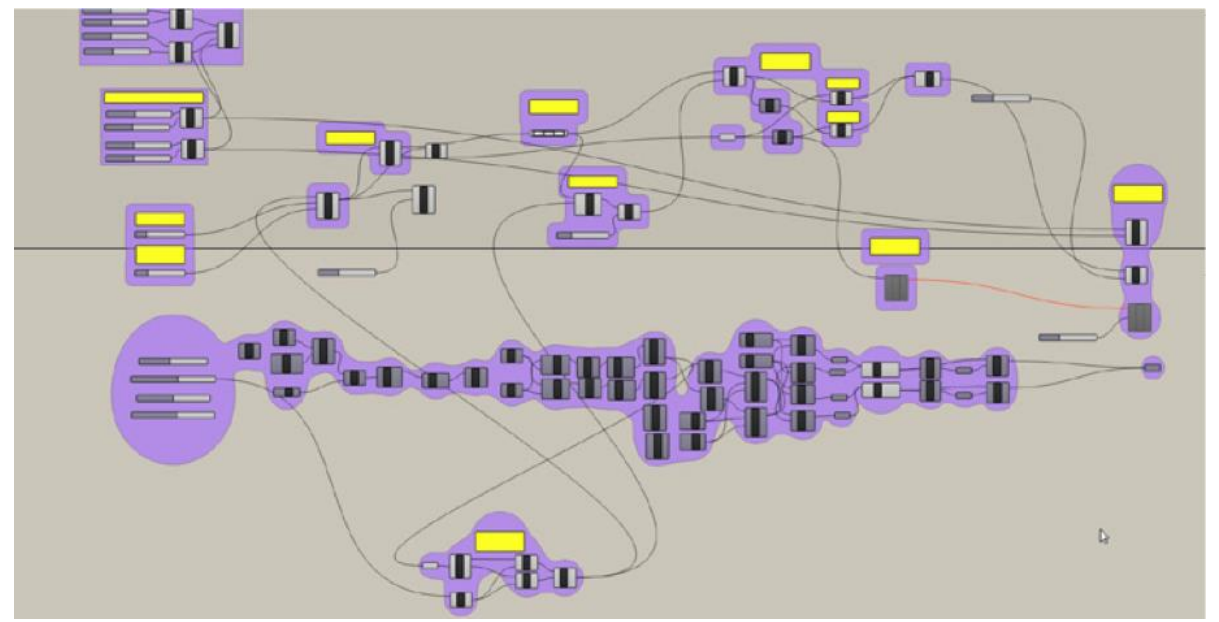

Figura 7 - Módulos de construção das "estrelas" e dos "waffles". 
A segunda rotina implementada trabalha com o mesmo tipo de lógica anterior. Mas a diferença é que parte de formas pré-definidas. Essas formas nomeadas "espiral", "redemoinho", "vendaval" são parametricamente dimensionadas e distribuídas segundo as configurações dos "waffles". O que em muito facilita a geração de inúmeras possibilidades de configurações.

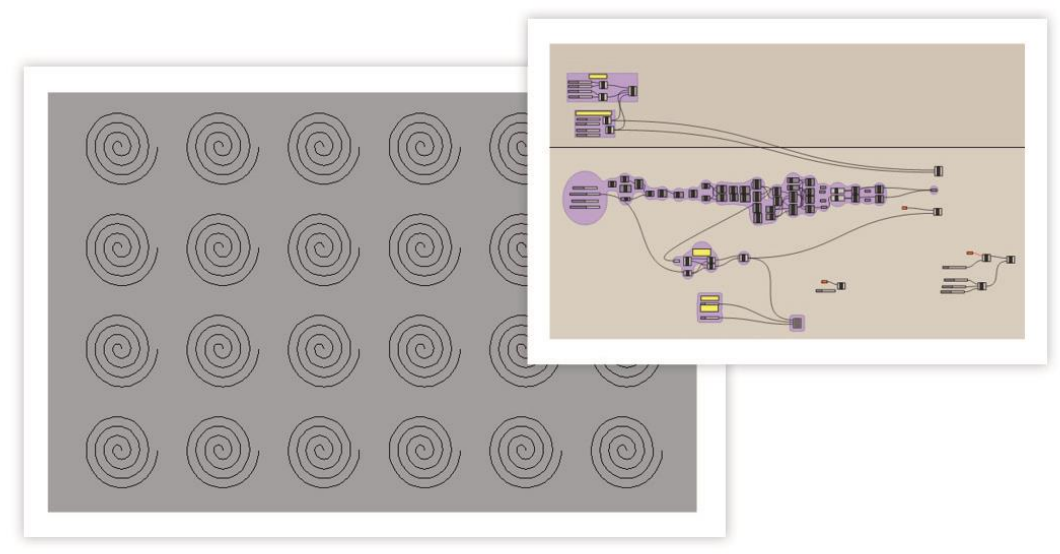

Figura 8- Modelo Espiral.

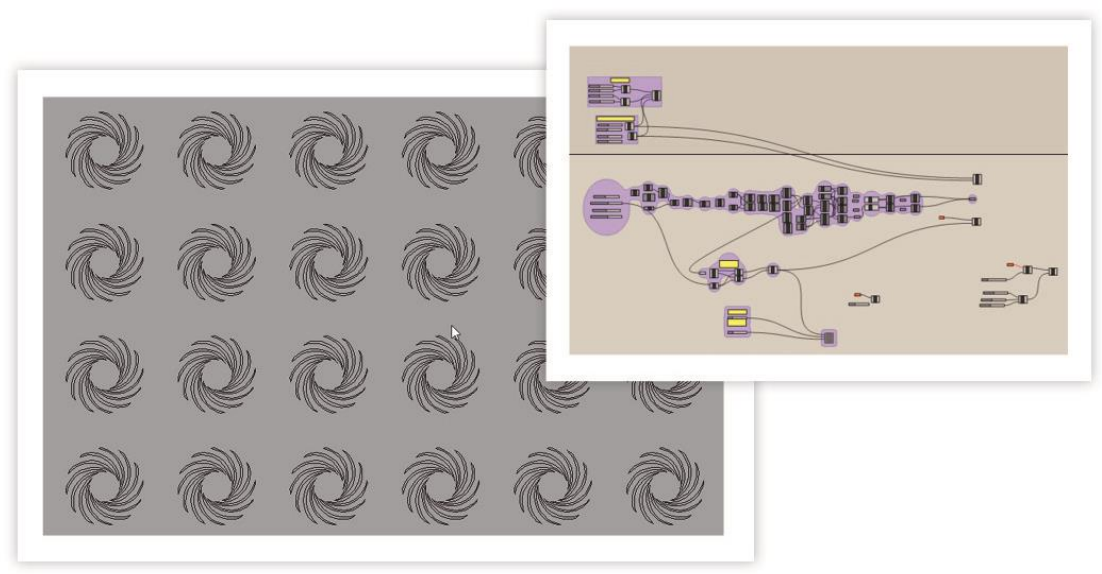

Figura 9 - Modelo Redemoinho.

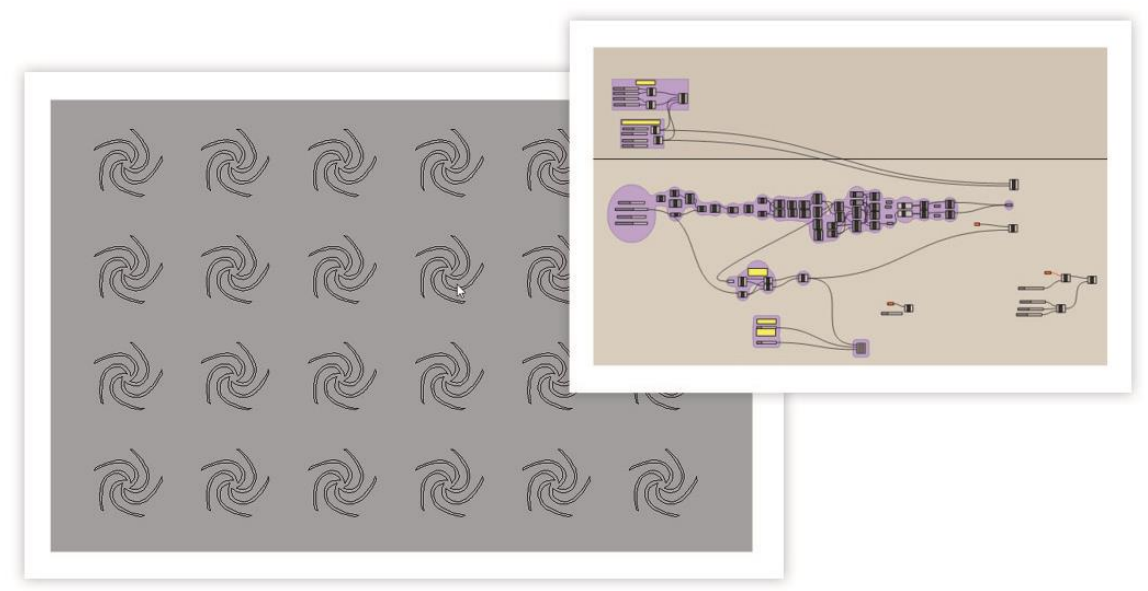


Figura 10 - Modelo Vendaval.

A rotina paramétrica que desenvolve os "waffles" também planifica e distribui economicamente suas partes, possibilitando rapidamente deixar o arquivo pronto para o corte a laser (Conforme a figura 11).

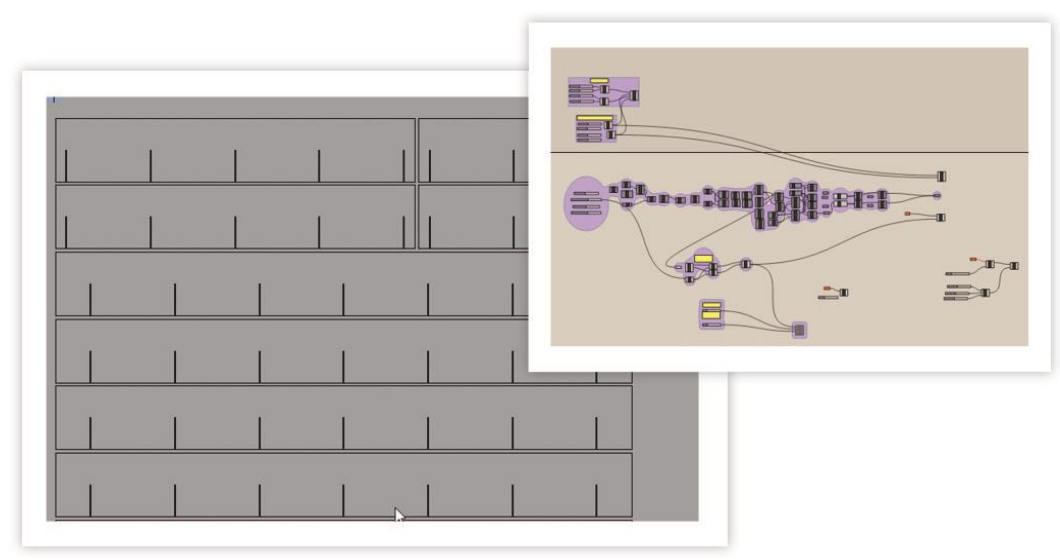

Figura 11 - Grade Estrutural Planificada (waffles).

É importante frisar que esse trabalho foi implementado a partir da adaptação de rotinas existentes no site do GRASSHOPPER - algorithmic modeling for Rhino em www.grasshopper3d.com/forum.

\section{PROJETO EXECUTIVO}

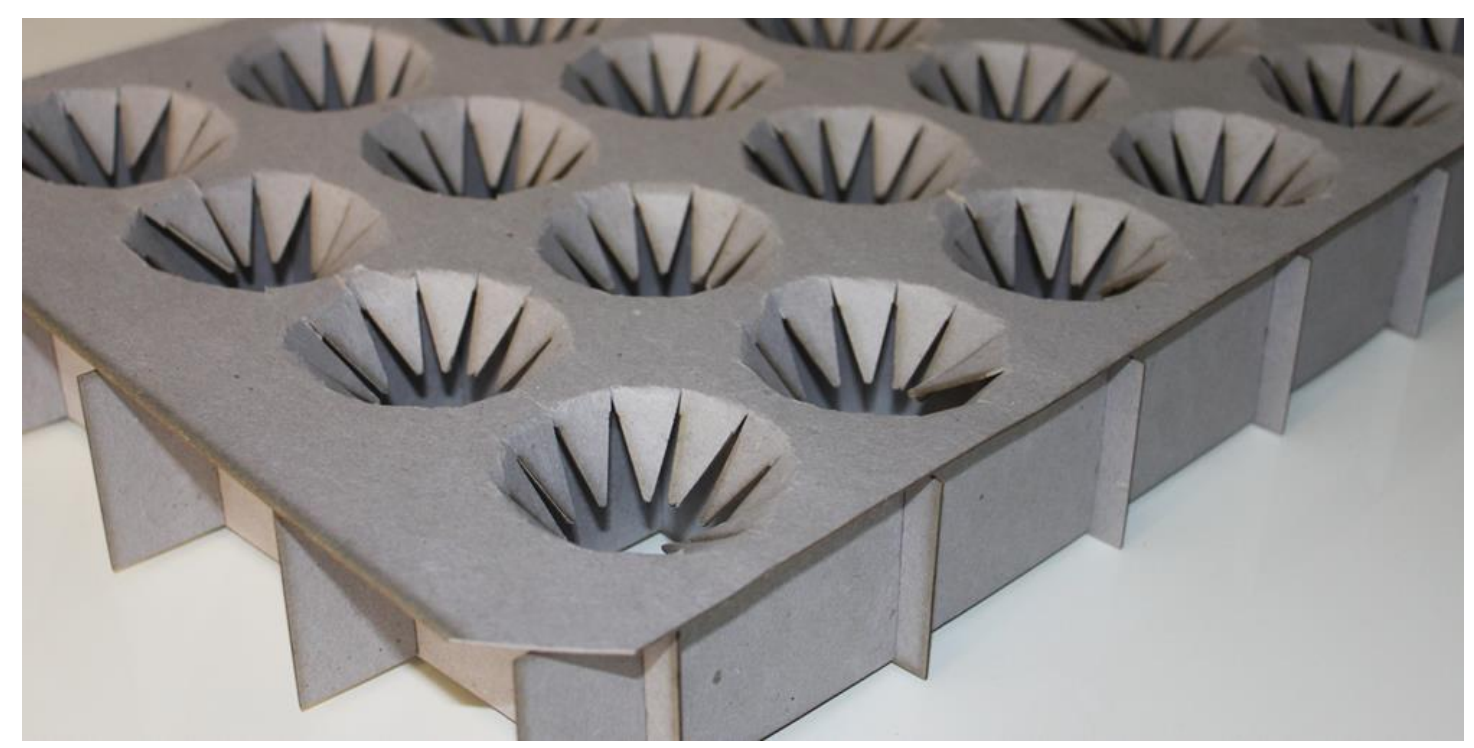

Figura 12 - Estrutura Montada.

A estrutura montada (figura 12) se mostrou bastante eficiente e resistente quanto a sua geometria. Faz com que as frutas fiquem separadas em seus nichos, sem sofrerem impactos durante a viagem. 


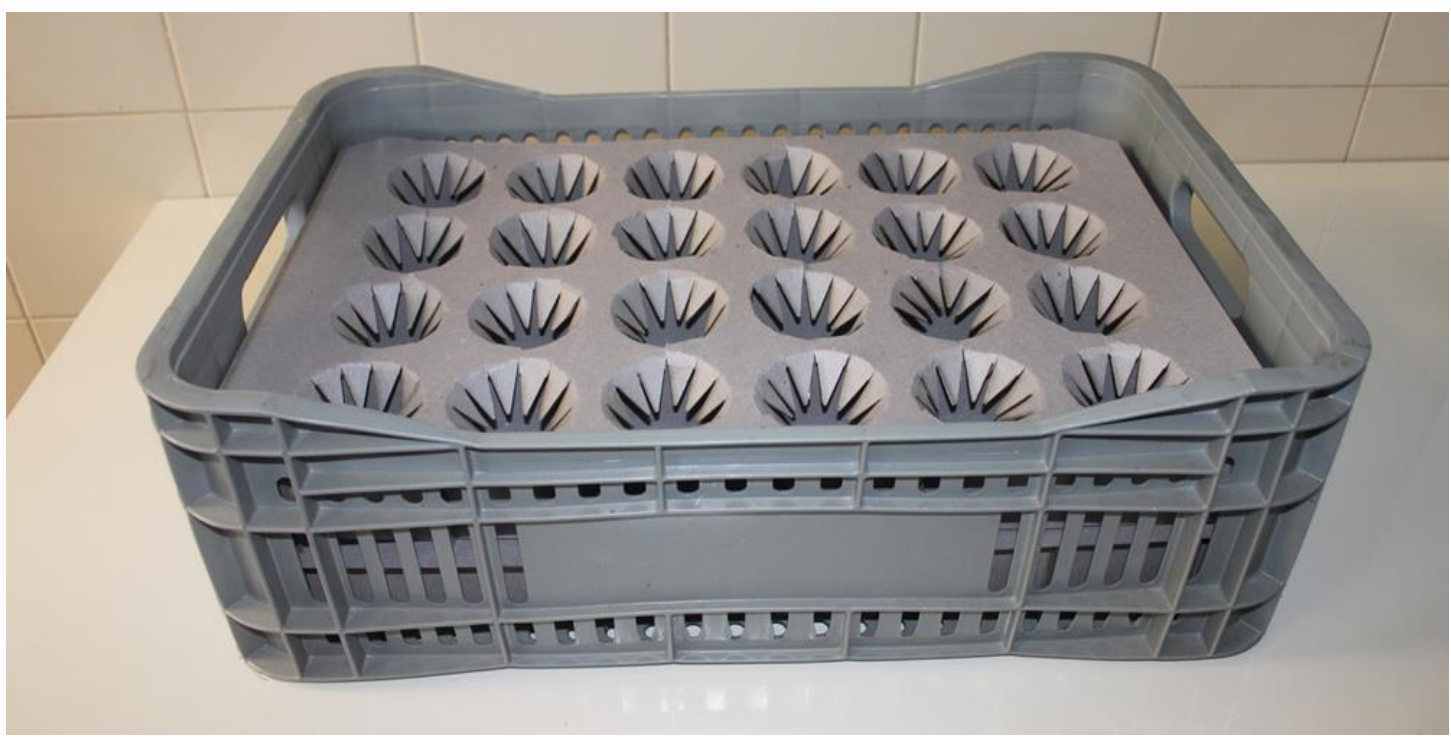

Figura 13 - Caixa com duas camadas.

As caixas de plásticos (figura 13) já existentes no mercado, muito utilizadas por feirantes, possuem duas alturas. No estudo realizado com as quatro frutas, é possível colocar duas camadas da estrutura na caixa mais baixa e quatro camadas na caixa mais alta. Resistindo mais aos impactos e consequentemente com um desperdício muito menor.

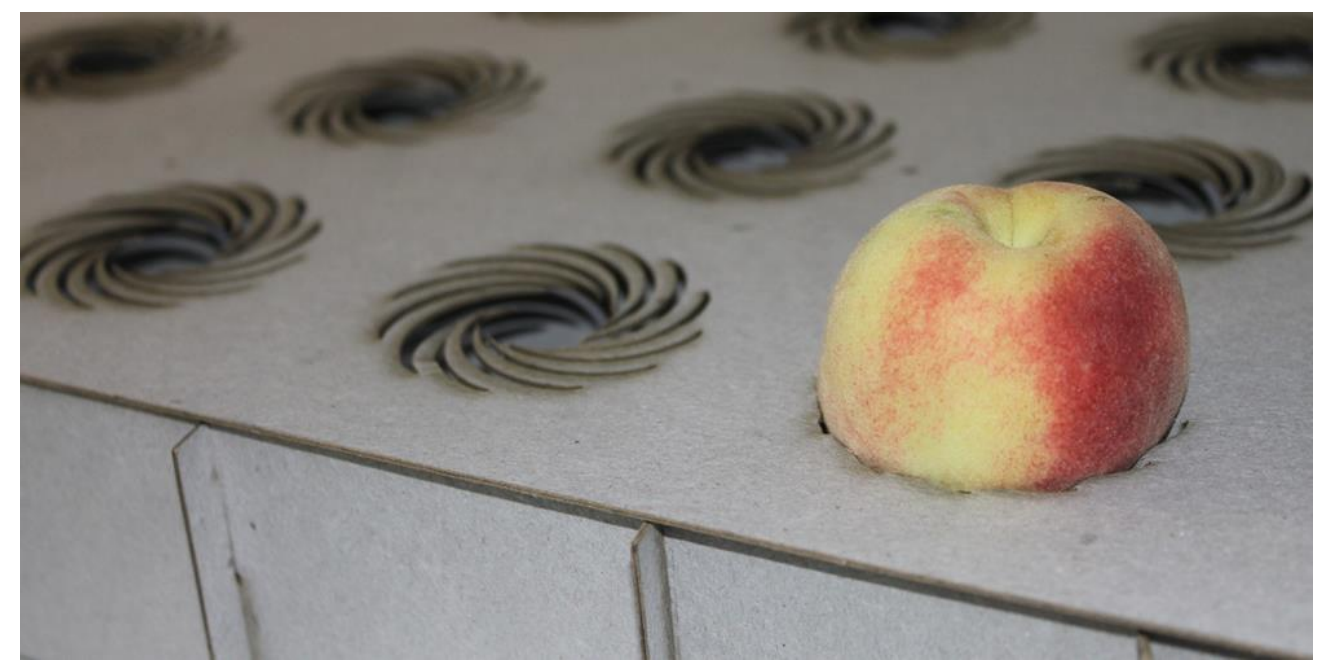

Figura 13 - Modelo Redemoinho para os pêssegos.

Nos testes realizados, o modelo vendaval se mostrou muito eficiente para frutas delicadas, como o pêssego (mostrado nas figura 13 e 14). 


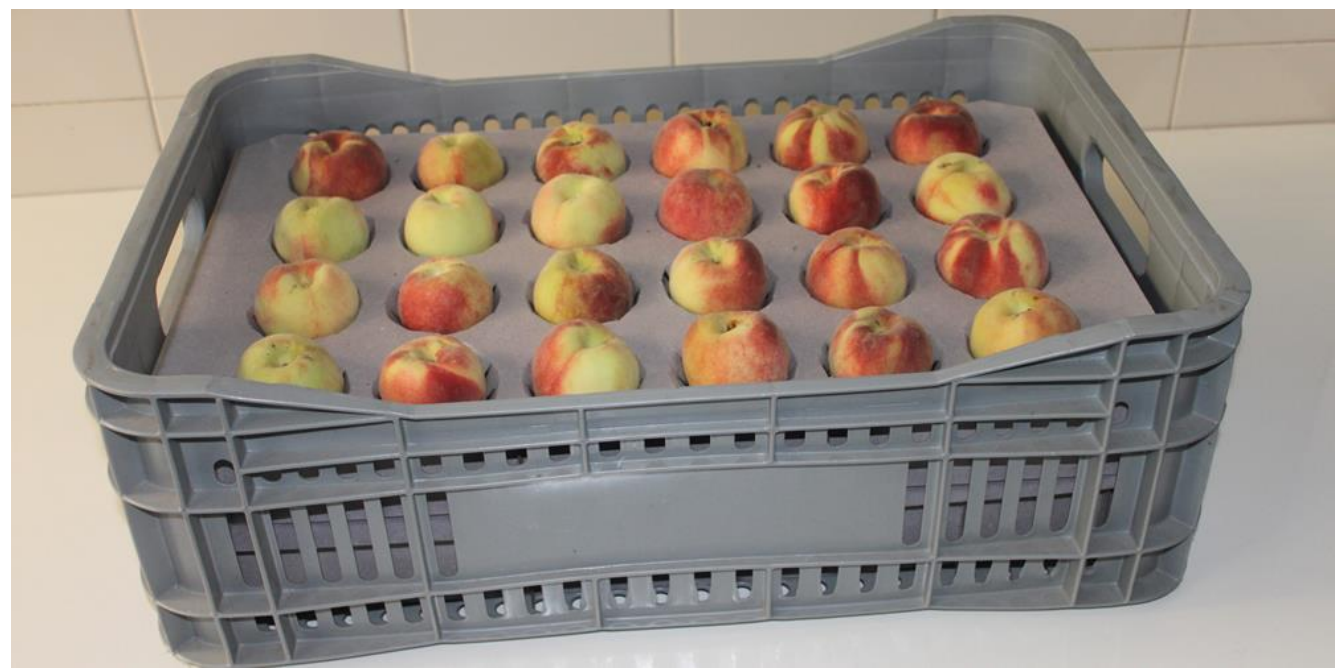

Figura 14 - Caixa com duas camadas para os pêssegos.

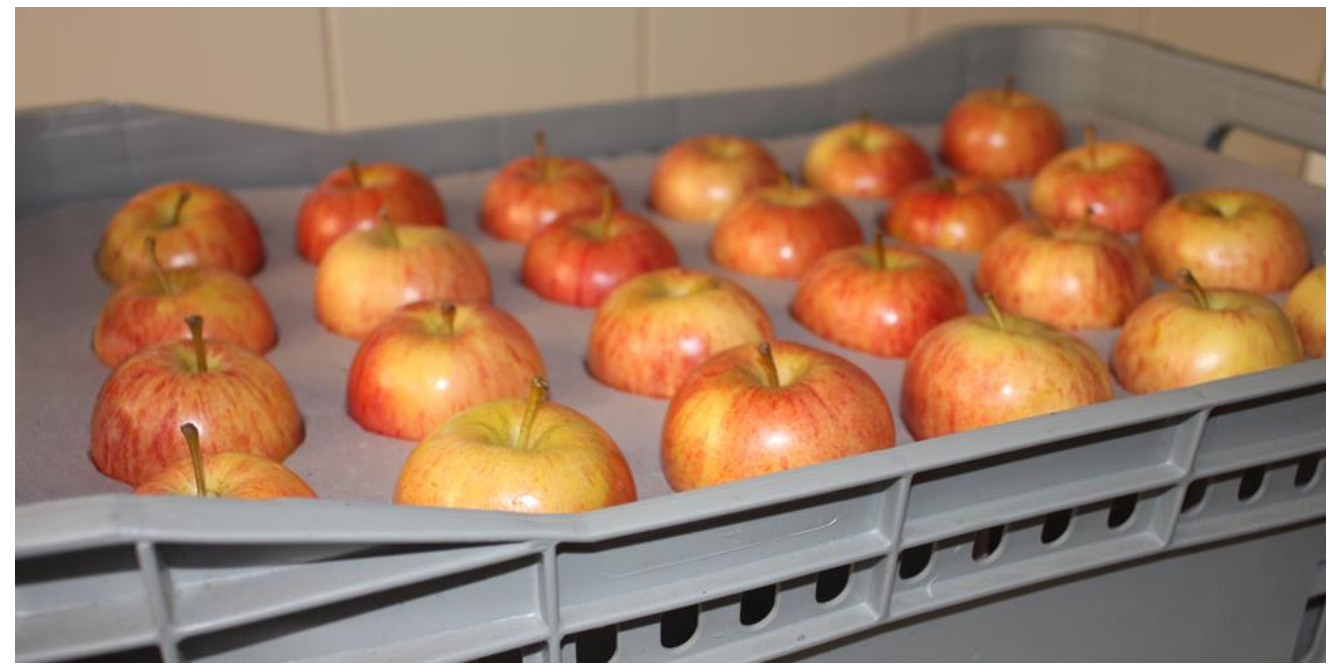

Figura 15 - Caixa com quatro camadas para as maçãs.

Já a maçã, fruta mais resistente, o modelo estrela, com 12 pontas, mostrou-se firme para segurar a fruta (conforme a figura 15).

\section{CONCLUSÃO}

O presente artigo teve como tema o processo de projeto de desenho de embalagem intermediária para transporte de frutas, onde foi desenvolvida a partir da proposição de utilizar-se o Plug-in GrassHopper para geração e modelagem paramétricas. Com esses dados, partiu-se de uma situação inicial bem definida, que estabelecia o caráter de flexibilidade dimensional para um grupo de frutas de morfologia semelhante. O resultado apresentado foi um conjunto de dois elementos distintos: o primeiro, uma superfície com nichos próprios para o acondicionamento de frutas; e o segundo, uma grade estrutural que permite o afastamento vertical das frutas, bem como, permite o empilhamento de diversas camadas de superfícies. Para ambas soluções apresentadas, o caráter de flexibilidade da programação dinâmica da geometria, possibilitou a concepção de inúmeros arranjos. As diferentes geometrias foram testadas e alteradas quando necessário. Tendo em vista que essas alterações de forma rápida foram possíveis graças a programação estruturada pelo Plug-in do GrassHopper e a geometrização das formas. 
Porem é importante ressaltar que outros trabalhos se fazem necessários para que o tema seja mais explorado, principalmente um estudo de materiais, para saber qual o melhor material a ser empregado, refletindo assim em melhorias para os usuários.

\section{REFERÊNCIAS}

BONSIEPE, Gui. Metodologia experimental: desenho industrial. Brasília: CNPq, 1984.

CARDOZO, G.A. Proposta de Jogo para a Solução de Problemas Não Estruturados com a Utilização de Técnicas Criativas. Dissertação (Mestrado em Design) - Programa de Pós-Graduação em Design, Universidade Federal do Rio Grande do Sul, Porto Alegre, 2012.

GOMES, Luiz Antônio Vidal de Negreiros. Criatividade e design: um livro de desenho industrial para projeto de produto. Porto Alegre: sCHDs, 2011.

DAVIDSON, Scott. Grasshopper: algorithmic modeling for Rhino. Lynnwood: United States, 2013. Disponível em: <http://literature.org/authors/carroll-lewis>. Acesso em 15 out. 2013

LOBACH, Bernd. Design industrial: bases para a configuração dos produtos industriais. São Paulo: E. Blucher, 2001.

BAXTER, Mike. Projeto de produto: guia prático para o design de novos produtos. 3. ed. - São Paulo: Blucher, 2011.

ONU, Nações Unidas no Brasil. Desperdício global de alimentos gera prejuízo de 750 bilhões de dólares por ano, calcula FAO. Brasil, 2013. Disponível em: < http://www.onu.org.br/>. Acesso em 23 out. 2013

ÉPOCA, Revista. Criada em impressora 3D, escova diz limpar os dentes em 6 segundos. Brasil, 2013. Disponível em: < http://www.onu.org.br/>. Acesso em 03 out. 2013

ROZENFELD, H. et al. Gestão de desenvolvimento de produtos: uma referência para a melhoria do processo. São Paulo: Saraiva, 2008.

BROD JÚNIOR, Marcos; Dr; GOMES, Luiz Vidal N.; PhD; MEDEIROS, Ligia S. de; Dr. Os Logogramas na prática da Educação Projetual. 9o Congresso Brasileiro de Pesquisa e Desenvolvimento em Design, 2010. 